\title{
De los herederos a los desheredados Juventud, capital escolar y trayectorias de vida
}

\author{
Oscar Dávila León, Felipe Ghiardo Soto ${ }^{1}$
}

\begin{abstract}
La escuela no es simplemente un lugar donde se aprenden cosas, saberes, técnicas, es también una institución que otorga títulos -es decir, derechos- y confiere al mismo tiempo aspiraciones.

El antiguo sistema escolar producía menos confusión que el sistema actual con sus ramificaciones complicadas, que provocan que las personas tengan aspiraciones mal ajustadas a sus oportunidades reales.
\end{abstract}

BourdieU, «La 'juventud' solo es una palabra» (2000).

\begin{abstract}
Resumen
En el texto, se discute la instalación de la escolarización como mecanismo legítimo de posicionamiento social en los jóvenes estudiantes del sistema público. No solo está cambiando las estrategias de reproducción en estos grupos sociales, sino que también como configuración de cambios culturales importantes que tienen que ver con la forma que se le quiere dar a la vida en el futuro, las edades que se le están asignando a cada uno de los hitos que marcan los pasos a la adultez y la valoración de las estructuras e instituciones familiares tradicionales.
\end{abstract}

Palabras clave: trayectorias de vida, transiciones a la vida adulta, condiciones juveniles.

\begin{abstract}
In the present article, the author discusses the setting up of schooling as a legitimate mechanism of social positioning in the young students of the public system. This is not only changing the reproduction strategies in these social groups, but also as configuration of important cultural changes that have to do with the structure to be given to life in the future, the ages being assigned to each one of the landmarks that mark the stages to adultness, and the value of the structures and traditional familiar institutions.
\end{abstract}

Key words: pathways of life, transitions to adult life, youthful conditions.

1 Investigadores del Centro de Estudios Sociales CIDPA, Valparaíso, Chile. E-Mail: oscar@cidpa.cl; felipe@cidpa.cl. El presente artículo se inscribe en el marco del proyecto de investigación «Trayectorias de vida y condiciones juveniles», el que ha contado con el apoyo de la Fundación Ford de Santiago de Chile. 
De los herederos a los desheredados Juventud, capital escolar y trayectorias de vida - O. Dávila, F. Ghiardo

\section{Introducción}

En el plano del discurso, el proyecto cultural que presenta la modernidad se propone sentar la razón como principio y herramienta para construir una nueva forma de pensamiento y organización social. En eso, la pedagogía como mecanismo, y la escuela como institución, jugarían un papel clave. No se podía lograr el proyecto de sociedad moderna si no se instauraba una institución que irradiara el pensamiento ilustrado. Tampoco si este seguía enfrascado en grupos reducidos. La modernidad se pretende expansiva, aspira llegar a cada rincón y a cada ser. Por eso, era necesario educar al conjunto de la población, única forma que la humanidad se liberara del fantasma de las creencias míticas que nublaban su mente y minaban sus posibilidades de progresar.

En el plano histórico, el devenir del proceso no fue todo lo fácil que se podría haber esperado. La modernidad es una abstracción que tiene una lógica, también un plan estratégico. Pero, en el mundo social que pretendía transformar, operaban fuerzas que golpearon su rostro y lo terminaron desfigurando. Si había producido avances en varios planos, no lograba fraguar en un orden social y político que garantizara el pleno goce de sus avances. Incluso, el campo que más había logrado desarrollarse, el de las ciencias, extravió su sentido durante las dos grandes guerras. No fue extraño, entonces, que la crítica a la modernidad se filtrara por todos lados y que también llegara al terreno de la Educación.

En 1964, Pierre Bourdieu y Jean-Claude Passeron ponían en el centro de la discusión las paradojas del sistema escolar. En Los herederos: los estudiantes y la cultura, el punto central era que la institución escolar, lejos de reducir las diferencias sociales, se había convertido en un mecanismo que mantenía o incluso profundizaba la distancia social entre las clases. Primero por su estructura, que ofrecía tipos de formación y guardaba destinos escolares diferenciados dependiendo de la clase que se tratara. La universidad, la instancia que mejor posición social garantiza, 
si bien no completamente, era casi exclusivamente patrimonio de los grupos con condiciones culturales, sociales y económicas privilegiadas. Segundo, por la carga simbólica que fue adquiriendo la institución escolar y los títulos que otorga, que terminaron trasladando al campo escolar la distribución de los signos de distinción y jerarquización social. Y, tercero, por los mecanismos internos con que operan las instituciones escolares, sobre todo los mecanismos para seleccionar el ingreso y la permanencia, que hacen parecer naturales condiciones que tienen raíces estructurales. Convencidos de que las diferencias no se explican por la herencia genética, sino por la herencia cultural y social, se resisten a creer que las diferencias de éxito en el curso escolar se deban a talentos innatos. Que unos ingresen a la universidad y otros queden fuera no responde a diferencias de capacidad, sino a las condiciones de origen que se traducen en ventajas para los grupos con mayor capital cultural, más impregnados del tipo de cultura que promueve la institución escolar.

Con estos argumentos, respaldados cada uno por evidencia empírica, los autores dieron un remezón que no dejó inmune a nadie con interés en el tema. En el marco de una Francia que recién se recomponía de la catástrofe de la guerra, que comenzaba a creer en la promesa del nuevo orden social que instauraba el Estado Benefactor, sus juicios venían a tocar la fibra más íntima de quienes habían vuelto a depositar su fe en el progreso y aguardaban confiados en las bondades de la institución escolar. La creencia ortodoxa asumía que su simple extensión sería suficiente para sostener un espiral de progreso cultural y material. Pero sus defensores no reparaban en los efectos que venían produciendo su estructura y sus lógicas de funcionamiento interno. El trabajo de Bourdieu y Passeron había señalado lo que no se veía o no se quería reconocer que se veía. No se trataba de cuestionar la institución escolar en sí misma, ni de negarle su potencia generadora de procesos sociales virtuosos. El ideal moderno también vale para ellos. Su preocupación está más bien puesta en develar las leyes de funcionamiento del sistema escolar, única forma de 
De los herederos a los desheredados Juventud, capital escolar y trayectorias de vida - O. Dávila, F. Ghiardo

minimizar su efecto en la reproducción de las asimetrías sociales (Bourdieu, 1998).

Si bien la crítica que elaboran Bourdieu y Passeron tiene por objeto el sistema escolar francés, específicamente el universitario, lo interesante es que el escenario que ofrecía en el período que estudiaron es, en varios puntos, análogo al chileno actual. En ambos países, quizás más en Chile que en Francia, el sistema escolar tiene una estructura que refleja la desigual distribución de capitales entre los grupos sociales y en ambos países ha terminado siendo un soporte para la reproducción de las diferencias sociales. También tiene rasgos comunes el desarrollo histórico de uno y otro sistema escolar. En ambos casos, la incorporación de los distintos grupos o clases se produjo a ritmos diferentes: primero las clases mejor posicionadas, luego las clases medias, que en buena parte surgieron y consolidaron su posición por el recurso escolar y, al último, los sectores populares, que mientras tanto habían seguido ligados al trabajo manual o industrial. Además, como en la Francia de los años sesenta, también en el Chile actual, el discurso sobre la educación goza de buena salud. Ya nadie parece cuestionar su validez y pertinencia. Hay un consenso general que la valida como elemento básico de cohesión social. De hecho, cualquier episodio que encierre un desajuste sistémico se atribuye a un «problema» o una «falta» de educación. Tampoco se cuestiona su validez como mecanismo legítimo de posicionamiento social. Ya es de sentido común que «para ser alguien en la vida» hay que estudiar y que la posesión de un título es la mayor garantía de un futuro más seguro. Ya no queda rincón sin una escuela ni clase que no se haya incorporado al sistema. Todos ocupan un asiento en el bus escolar, unos mejores que otros, pero todos uno. La cobertura del sistema en pocos años se ha elevado hasta alcanzar casi al ciento por ciento de la población en edad escolar. Todos los niños y jóvenes tienen que estar en el sistema y, si hasta hace poco la instrucción obligatoria eran seis años, hoy son doce. 
De este marco de situación, surgen los temas de interés del estudio desde el cual se construye este texto (Dávila, Ghiardo y Medrano; 2006), que apunta a relevar los efectos que está produciendo el proceso de escolarización en quienes permanecen en el sistema municipal, que en Chile concentra a las clases más desfavorecidas y a los grupos de más tardía incorporación al sistema escolar. El propósito del estudio referenciado fue intentar describir las principales tendencias en las trayectorias de los jóvenes que estudian en el sistema municipalizado, incluyendo distintas realidades sociales y educativas. Para eso, se tomó como universo de población la que asiste a la educación secundaria del sistema municipalizado de tres comunas de la V Región de Valparaíso: Puchuncaví, Quillota y Viña del Mar, compuesto en total por doce establecimientos. La metodología consistió en la aplicación de una encuesta -un cuestionario de autoaplicación-. La construcción de la muestra siguió un criterio de saturación y la muestra efectiva llegó a los 6.496 casos, que corresponde al total de estudiantes que asistieron a clases el día que se aplicó el instrumento. Complementariamente, se efectuaron cinco grupos de discusión temáticos, que permitieron un mejor acercamiento a los componentes de los discursos que elaboran estos jóvenes al referirse a la educación, el futuro y la condición juvenil.

A diferencia de Bourdieu y Passeron, nuestro interés no se centró en los herederos, sino en los desheredados; no en los que reciben buenas dotes de los distintos tipos de capital, sino en los que provienen de los grupos con bajos niveles de capital cultural, social y económico a la vez. Creemos que ellos son los actores de cambios culturales importantes que se están produciendo en el seno de estos grupos, los portadores de una nueva «visión de mundo», distinta a la que tuvieron anteriores generaciones y que, por eso, podría encerrar dilemas de sentido o tensiones subjetivas que es necesario pesquisar.

Primero, porque el curso de vida que propone el discurso de la escuela significa un giro en las estrategias de reproducción de 
De los herederos a los desheredados Juventud, capital escolar y trayectorias de vida - O. Dávila, F. Ghiardo

estos grupos. Si antes el destino más común para un joven de sectores populares era el trabajo -o el hogar para una joven-y los estudios quedaban restringidos a los hijos «más dotados», casi siempre varones, la permanencia de casi la totalidad de sus miembros más jóvenes en establecimientos escolares estaría transformando la manera en que se enfrenta el futuro, lo que se anhela y lo que se proyecta como futuro válido. Para los miembros jóvenes de estos grupos, cada vez sirve menos abandonar los estudios para entrar al mundo del trabajo. Su incorporación al sistema escolar parece ser definitiva. El problema se viene cuando tienen que resolver la tensión entre las estrategias de reproducción que han sido más efectivas para las anteriores generaciones del grupo o la clase y la efectividad de la estrategia escolar.

Segundo, porque la permanencia en el sistema escolar creemos que estaría modificando la concepción del tiempo y el modo en que se planifican los propios tiempos vitales. Para estos jóvenes, la etapa escolar se está prolongando. A la edad en que el abuelo o el padre ya trabajaban o la madre manejaba un hogar, ellos permanecen en el liceo. Incluso es probable que muchos continúen estudiando. La condición de estudiante se hace más larga y, con ello, se modifican las condiciones en que se es joven, e incluso al significado mismo que adquiere la palabra juventud.

El desarrollo y análisis de algunos de estos temas es lo que se presenta en este trabajo. Se inicia con una introducción centrada en las discusiones contemporáneas sobre los roles y funciones a cumplir por la Educación. Luego se intenta construir una postura que permita ligar los procesos que se viven en esta etapa con el fondo estructural desde donde se construyen los universos de significado que le dan sentido a las acciones de los sujetos. Y se concluye con el análisis de los efectos culturales o subjetivos que está produciendo el proceso de escolarización: Cuáles son las miradas que están produciendo estos jóvenes sobre el futuro, en qué medida esas miradas están reflejando nuevas condiciones juveniles o nuevas formas de vivir la juventud, cuáles son las prin- 
cipales vertientes que estarían siguiendo estas transformaciones culturales.

\section{El contexto educativo en las trayectorias juveniles}

La educación es uno de esos componentes esenciales para cualquier forma de organización humana. De ella dependen tanto la transmisión de sus bases culturales como las posibilidades de adaptarse a los cambios del entorno. No resulta extraño, entonces, que nadie dude sobre la gravedad que ejerce para la estabilidad de las sociedades contemporáneas. Su importancia es tal que de lo que ocurra en materia de Educación pareciera depender su futuro. Sin educación masiva, dice el Informe de la Comisión Nacional para la Modernización de la Educación, no hay posibilidad de pensar en una «cultura nacional» vigorosa y de sólidas raíces, ni en la idea de patria, ni en una vida civilizada, y menos en la democracia como forma de vida (CNME, 1995). Junto al desarrollo del conocimiento, ha sido puesta como el desafío más urgente para los países en desarrollo, el piso mínimo para la «transformación productiva con equidad», como titula el informe de la CEPAL, la clave para superar la pobreza, modernizar los códigos culturales de la población, ganar en competitividad y enfrentar en buenas condiciones «los desafíos del siglo xxI» o de la «sociedad globalizada». Como alguna vez fueran los recursos naturales, hoy es la Educación el principal componente de la riqueza de las naciones. El lema del Ministerio de Educación -La educación es nuestra riqueza- expresa claramente esa convicción.

Pero, si hay consenso sobre su relevancia, tampoco parece haber dos opiniones respecto a la incertidumbre en que se encuentra. El hecho mismo de que los distintos informes y diagnósticos que se le hicieron a mediados de la pasada década coincidieran en la necesidad de reformar el sistema escolar es ya un indicador bastante expresivo de la magnitud de sus dilemas. No hay elemento que intervenga en educación que escape o que- 
De los herederos a los desheredados Juventud, capital escolar y trayectorias de vida - O. Dávila, F. Ghiardo

de fuera. Todos se han hecho insuficientes para responder a los desafíos que imponen las transformaciones de esta nueva era y, por eso mismo, todos requieren ser reformulados. «Debemos preguntarnos una vez más -dice el mismo informe-, igual como hicieron nuestros antepasados, qué es necesario aprender y qué se debe enseñar a los niños y jóvenes que vivirán en el próximo siglo; mediante qué métodos pedagógicos, a fin de despertar y cultivar todas sus capacidades; quién debe encargarse de la educación, y cómo conviene organizarla a fin de que su servicio sea equitativo, de calidad y use eficientemente los recursos que el país le destina» (CNME, 1995:25). Hay problemas prácticos que son inevitables, pero todos ellos recaen, en el fondo, en el problema del «sentido» mismo de la educación, que no es sino un problema de fondo «filosófico». «Existe una dependencia estrecha y esencial -dice De Azevedo-, inherente a la naturaleza misma del proceso pedagógico, entre la educación y una concepción de la vida que aparece 'explícitamente formulada en un sistema o implícitamente supuesta' en la estructura escolar, en los programas, en los conocimientos que se ofrecen o se ocultan, en los actos del educador y en las técnicas de trabajo» (De Azevedo, 1949: 325). Como plantea el mismo autor, esto coloca a la Educación frente al problema del tipo-ideal-de hombres (y mujeres) que se busca crear y del mundo o sociedad que se pretende construir. Sobre este punto, no parece haber duda. Eso, al menos en las máximas esferas internacionales que discuten sobre el tema. Como dice el informe de la UNESCO sobre educación secundaria, «Todos somos conscientes de que la educación de nuestros jóvenes será decisiva para el tipo de sociedad que se establecerá en el futuro, tanto en lo que se refiere a su desarrollo como del punto de vista de los valores en los que se sustentará y las normas de convivencia que regirán» (Macedo y Katzkowicz, 2001:7).

Ahora bien, la asignación de sentidos a objetos y fenómenos, como muchos se han encargado de demostrar, es un proceso histórico no exento, por tanto, de vaivenes y conflictos. Y, si tenemos en cuenta la diversidad de «proyectos de sociedad» que se 
han intentado fundar en estos últimos siglos, sobre todo después del período que Hobsbawm llama de la «doble revolución» (cfr. Hobsbawm, 1994), se comprende que no haya existido ni pueda hoy existir una sola mirada que logre imponer un solo sentido a la Educación. Este es, digamos, un terreno en disputa, cuya discusión no puede desentenderse del conjunto de significados precedentes. No puede pasar por alto, por ejemplo, el tono profético que le diera el pensamiento Ilustrado, ni la disputa entre la postura liberal y el Estado Docente, o la influencia de los enfoques desarrollistas de los años cuarenta, de la educación popular de los sesenta y de la escuela única de los setenta. Todos ellos han dejado su huella en la discusión «filosófica» sobre la Educación, y uno y otro son recreados en la medida que algún grupo los recoge y apropia. De ahí que los dilemas presentes de la Educación se encuentren atados a la diversidad de visiones, discursos, posturas o ideologías que han intentado y siguen intentando definir su esencia y resolver sus problemas.

Este mismo carácter histórico de la asignación de sentido hace que los dilemas de la Educación estén irremediablemente ligados al desarrollo histórico de la institución que la imparte. El punto clave e inevitable en esto es señalar el enorme peso que ha venido adquiriendo la institución escolar para el conjunto de la vida social. Aquí son muchos y de distinto orden los aspectos necesarios a tener en cuenta, pero todos están directa o indirectamente ligados a la «evolución» de los sistemas escolares modernos. Solamente en términos de infraestructura, su crecimiento es notable. En su Historia de la enseñanza en Chile, Amanda Labarca señala lo escaso que era el número de establecimientos y lo precarias que fueron las condiciones de la infraestructura escolar en los albores del sistema de enseñanza (cfr. Labarca, 1939). La misma autora describe su evolución hasta la cuarta década del siglo $\mathrm{xx}$, que, pese a mostrar un comportamiento errático, con períodos de crecimiento y otros de estancamiento, en la sumatoria muestran una clara tendencia hacia la expansión y mejora de la infraestructura escolar. Esa es la tendencia que ha seguido 
De los herederos a los desheredados Juventud, capital escolar y trayectorias de vida - O. Dávila, F. Ghiardo

desde ese tiempo hasta esta parte, al punto de que hoy en día prácticamente no queda rincón del país sin un establecimiento escolar. Baste considerar que el año 2003 llegaban a los 11.223, que el destinado a infraestructura ha sido uno de los ítemes de gasto más abultados del presupuesto en educación, y la ampliación y mejora de los establecimientos el efecto más visible de la actual Reforma Educacional.

Consustancial a este crecimiento de la infraestructura es el progresivo aumento en los niveles de cobertura y matrícula. En Chile, desde que se fundaran los primeros establecimientos de educación formal hasta la presente década, las proporciones de población que han pasado algún momento de sus vidas por los pasillos de un establecimiento escolar vienen siendo cada vez mayores. A fines del siglo xIX, por ejemplo, de un millón y medio de habitantes que tenía el país, un $25 \%$ se encontraba en edad escolar, pero solo el 13\% de la población accedía a una educación formal (PNUD, 1998). En el transcurso de los novecientos, con la obligatoriedad de la educación primaria y el explosivo aumento de la población, la asistencia al sistema escolar se expande considerablemente. Según Labarca, en 1936, de una población total de 4.531.051 habitantes, la educación primaria contaba 568.700 alumnos y 41.893 la secundaria (Labarca, 1939). Posteriormente, en 1952, el 16,4\% de la población entre 15 y 19 años se encontraba matriculado en la enseñanza secundaria, porcentaje que, en 1960, sube a un $31 \%$, y, en 1970, a un 34\%. A poco andar el siglo xxi, cerca del 96\% de los niños está cursando el ciclo básico, y del 92,6\% de los jóvenes, el secundario (Mideplan, 2004).

Tan importante como los dos puntos anteriores es la progresiva extensión del tiempo que dura la formación escolar. En los primeros lustros de existencia de las instituciones escolares modernas, el ingreso se producía alrededor de los doce años de edad, las clases se impartían dos o tres veces a la semana y durante un período de dos a tres horas por jornada (cfr. Labarca, 1939). Esta situación difiere ampliamente de la actual, en que la edad de 
ingreso es cada vez más temprana y más tardía la de egreso. El notable crecimiento de la cobertura en educación pre-escolar, que ha pasado a ser prácticamente educación obligatoria, anexada incluso físicamente al espacio de la escuela, ha venido adelantando a los tres o cuatro años la edad de ingreso al sistema escolar de una proporción cada vez mayor de niños. Paralelamente, si hasta hace poco la ley prescribía como obligatoria la instrucción primaria, recientemente se promulgó la nueva ley que declara obligatoria la educación secundaria, prolongando de esta manera hasta los 17 ó 18 años la permanencia mínima en la institución escolar. La misma tendencia corre para la duración de las jornadas escolares que, de solo unas horas a la semana, se apronta a dar el salto decisivo con la implementación del régimen de Jornada Escolar Completa en todos los establecimientos escolares de Chile.

Lo importante de este conjunto de tendencias es que, si alguna vez distaba de ser un espacio de socialización que le hiciera el peso a la familia y a los espacios cotidianos de interacción, el escolar, aunque no es el primario, ha llegado a ser el más gravitante de las sociedades contemporáneas. Esto no solo porque constituye una fuente permanente de vivencias para casi la totalidad de los niños y jóvenes, sino porque los ciclos que ella define son los que, en definitiva, regulan los ciclos vitales de los sujetos. Esto no es menor, sobre todo si tenemos en cuenta que es justamente en este doble proceso de extensión del sistema escolar y ampliación del tiempo de escolarización donde se encuentra la fuente histórica de la juventud como «etapa de la vida» y como «categoría social» (cfr. Alba, 1975). Lo relevante de la situación actual es que la condición de joven ha dejado de ser privativa de los sectores más privilegiados. Pues, en efecto, la experiencia de un período de preparación para la «vida adulta» (productiva) o para la continuación de estudios superiores, que es, por definición, la finalidad de la educación secundaria, estuvo desde sus inicios y durante largo tiempo restringida a los miembros jóvenes -casi siempre varones- de la aristocracia y la oligarquía y, aunque se hizo extensiva luego a los de sectores medios, por lo general se 
De los herederos a los desheredados Juventud, capital escolar y trayectorias de vida - O. Dávila, F. Ghiardo

mantuvo ajena a las vivencias habituales de los jóvenes de sectores populares. Para ellos y ellas, lo más habitual era permanecer pocos años en la escuela e incluso muchos la abandonaban sin siquiera completar el ciclo primario obligatorio. Más que por la vía de los estudios, las alternativas para construir su vida convergían, por lo general, y desde temprana edad, en el camino del trabajo u otra actividad de sobrevivencia. Por eso, su «juventud» era breve. $\mathrm{Y}$ eso, si es que se llegaba a producir una etapa que pudiera recibir ese nombre, pues lo más común era que entre la infancia y la adultez no hubiera intermedio, que se pasara a ser «adulto» siendo todavía un niño.

En este sentido, uno de los efectos socioculturales más relevantes que acompañan la masiva incorporación y permanencia en la educación secundaria de sujetos provenientes de los sectores populares, ha sido la producción de nuevas «condiciones juveniles». Ciertamente, como plantean algunos autores, este mismo proceso vino a diversificar los componentes de la palabra juventud, al punto de forzar a hablar de «juventudes» (cfr. Tedesco, 2000). Sin embargo, es innegable que, al ser la de estudiante secundario una condición vivida simultáneamente por casi la totalidad de una misma generación, en cierta medida la institución escolar termina estandarizando $u$ homogeneizando -nominalmente- la estructura o la forma en que se ordenan los «ciclos vitales» de los sujetos, eso al menos hasta lo que dura el ciclo secundario.

Pero quizás donde más se notan los efectos socioculturales que ha venido produciendo la consolidación de la institución escolar es cuando se observa su influencia a nivel de la estructura social misma. No se puede negar que uno de los procesos sociales más importantes que ha arrastrado la escolarización masiva es que ha contribuido a modificar la estructura de clases de las sociedades modernas, aunque fuera promoviendo «ascensos» individuales en la «escala social». De hecho, la formación y fragmentación de las clases medias, que es uno de sus procesos más característicos, le debe mucho a la masificación de la enseñanza. 
Lo mismo la incorporación masiva de las mujeres al mundo del trabajo productivo (PNUD, 1998). Varios trabajos que han analizado las transformaciones en la estructura de clases (Atria, 2004), o el proceso de estratificación social (Wormald y Torche, 2004) coinciden en que la escolaridad constituye un factor explicativo ineludible. La cantidad de años de estudios y los títulos que otorga la institución escolar se han transformado en los códigos básicos que regulan el acceso y definen la estructura del «mundo del trabajo». De ahí que estos atributos quepan dentro de los factores que más fuerte determinan la posición que ocupa un individuo en la sociedad, su status y nivel de ingresos, el grupo al que pertenece y la forma o «estilo» de vida que adopta. En este sentido, Bourdieu decía que la escolaridad es el instrumento de reproducción que adquiere mayor legitimidad en las sociedades contemporáneas (Bourdieu, 1994). Y también se entiende que el «discurso escolar» sea uno de los más potentes y con mejor acogida entre el conjunto de la población. La creencia en las posibilidades que entrega esta herramienta es sumamente extendida. Los resultados de la encuesta a los actores del sistema educativo realizada por el Centro de Investigación y Desarrollo de la Educación (CIDE) es un buen reflejo de cómo viene creciendo la fe depositada en la educación formal. Entre la medición realizada el año 2000 y la del 2003, tanto en alumnos como en apoderados, se evidencia un aumento sostenido en la proporción que asume como meta la educación universitaria completa ${ }^{2}$. La misma convicción se observa al revisar cómo crece la cantidad de personas que apuestan ingresar al sistema universitario. Según datos del Departamento de Registro de Educación Superior (DEMRE) de la Universidad de Chile, la cantidad de individuos inscritos a las pruebas de selección universitaria presenta un aumento sostenido en toda la última década, y llegaba a los 159.249 el año 2004 (Universidad de Chile, 2004). Lo mismo ocurre con los niveles de

2 El año 2000, de los alumnos encuestados, el 58,7\% pensaba en llegar a completar una formación de nivel universitaria. Tres años después, ese porcentaje había subido al $64,4 \%$ (CIDE, 2003). 
De los herederos a los desheredados Juventud, capital escolar y trayectorias de vida - O. Dávila, F. Ghiardo

matrícula en el sistema de educación superior. Solamente considerando el sistema universitario, que hasta 1981 era su único componente, se observa un crecimiento tanto en términos netos como proporcionales. En 1950, por ejemplo, los estudiantes universitarios chilenos se contaban en 11 mil, la matrícula casi se triplica desde aproximadamente 20 mil en 1957 a más de 55 mil alumnos en 1967; y, pese a que, a partir de 1975 y hasta 1980, con el cierre de carreras impuesta por las autoridades durante la dictadura, se produjera una caída de un 30\%, la tendencia al alza se recupera y ya en 1983 llega a los 108. 843 estudiantes, a 223. 889 en 1995 y el año 2004 alcanza los 392.294 solo en el nivel universitario, que dentro del sistema de educación superior, concentra la mayor cantidad de matrícula (Universidad de Chile, 2004). Ahora, si a esto se suma la matrícula en los Institutos Profesionales y Centros de Formación Técnica, el total de individuos que están cursando algún estudio de nivel superior aumenta, para llegar, según datos que corresponden al año 2003, a los 567.114 (Mineduc, 2003).

En este escenario, en que el recurso a la herramienta escolar ha llegado a ser una estrategia de reproducción (cfr. Bourdieu, 1994) ya instalada en la «mentalidad» y las prácticas mismas de las distintas clases sociales, los más grandes dilemas y las mayores dificultades que enfrentan los sistemas educativos, y que alcanzan, por tanto, al sentido de la Educación, se producen, paradójicamente, por la potencia que adquirió este discurso. Pues si por un lado es cada vez mayor la cantidad de personas que cree y apuesta por el curso de los estudios, si las máximas aspiraciones de una gran mayoría de la población apuntan a seguir estudios de nivel superior, sobre todo universitarios, es un hecho de la causa que las posibilidades para lograrlo no han estado ni están equitativamente distribuidas.

El efecto que produce la permanencia de esta estructura sobre las posibilidades de trayectoria de los jóvenes es bastante claro. Sobre esto, el Informe del PNUD es tajante cuando plantea 
que «A fines de la educación primaria ya está pues fijada, en grado importante, la trayectoria de los jóvenes» (PNUD, 1998:178). Pese a los aumentos en los dineros destinados a educación y pese también a algunos avances que se observan en términos de la efectividad con que han actuado algunos establecimientos municipalizados (cfr. Redondo, 2005), los efectos de estas tendencias son el principal componente del terreno incierto en que hoy se mueve la educación. En materia de educación, dice Tedesco, «la gran pregunta pasa por la posibilidad de educar en condiciones de alta inequidad social» (Tedesco, 2000:14). Como dice Jesús Redondo, la «igualdad de oportunidades» es el gran mito de la Reforma Educativa (Redondo, 2005). Los avances en términos de cobertura son innegables y sin duda han contribuido a aumentar los niveles de escolaridad de la población en general y de los sectores de más escasos recursos en particular, pero esto solo significó el traslado del problema de la educación desde el del acceso al del rendimiento (Cassassus, 2002). El punto está en que diversos estudios demuestran que muchos de los factores que explican las diferencias de rendimiento están relacionados con el «acervo cultural» (León y Martínez, 2001) o los niveles de «capital cultural» (Bourdieu, 1994) que hereda cada nueva generación, definidos principalmente por el nivel de escolaridad de los padres, y en especial, de las madres. En este sentido, los desfases en los tiempos de incorporación al sistema escolar -y al tipo de cultura que imparte- que hubo entre las distintas clases en el pasado, se traducen hoy en una desventaja comparativa que afecta a los jóvenes de las clases menos escolarizadas. Las pruebas estandarizadas de medición constituyen una demostración que deja en evidencia la curvatura del círculo que cierra el sistema escolar chileno. Más allá de todo lo cuestionables que puedan llegar a ser, o de lo perversos que sean los usos dados a sus resultados, en cada nueva medición de la prueba del Sistema de Medición de la Calidad de la Educación (SIMCE), los datos se encargan de recordar la distancia que persiste entre los resultados que obtiene la educación particular pagada respecto a los establecimientos que pertenecen 
De los herederos a los desheredados Juventud, capital escolar y trayectorias de vida - O. Dávila, F. Ghiardo

al sistema público de educación, y, entre estos, por sobre todo, al sistema municipalizado. En la misma dirección, apuntan los resultados de cada nuevo proceso anual de ingreso al sistema universitario. Solamente considerando el más reciente, se observa que, de los 65.500 alumnos del sistema municipalizado que rindieron la Prueba de Selección Universitaria (PSU), solamente 16.860 -el $25 \%$ - finalmente quedaron matriculados en una universidad, porcentaje que sube al $27 \%$ entre quienes pertenecen al particular subvencionado, y que llega al 34\% de los que pertenecen al particular pagado (Universidad de Chile, 2004). Eso con relación a los que rindieron la prueba de selección universitaria. Pues, si la relación se intenta establecer con respecto al total de la matrícula, resulta que la proporción de matriculados que proviene del sistema municipalizado representa aproximadamente al $3 \%$ del total de esta población, sube al 4,8\% en el caso de la que asiste al sistema particular subvencionado y al 10\% del particular pagado $^{3}$.

Este conjunto de tendencias demuestra que el escenario para quienes cursan sus estudios secundarios en establecimientos municipalizados es, por decir lo menos, bastante más complejo que el de aquellos que estudian en los otros dos sistemas. Para ellos, más que para los otros de su misma edad, la pregunta por el para qué educarse pasa a ser un nudo crítico que los enfrenta a múltiples tensiones. El solo hecho de que la deserción escolar se produzca en los primeros dos años de la enseñanza secundaria y se concentre en los establecimientos municipalizados señala la tensión que ya presenta el hecho mismo de permanecer en la educación secundaria. Luego de terminarla, que es la decisión más común, muchos deben resolver una segunda tensión, esta vez entre el camino de los estudios y el del trabajo. La cada vez más amplia oferta de carreras que muestra el mercado educati-

3 Este dato se obtuvo relacionando el total de la matrícula en cada subsistema secundario con los datos de matrícula universitaria proporcionados por el compendio estadístico del DEMRE. 
vo es una vitrina inagotable de futuros posibles, pero entre los estudiantes del sistema municipalizado no hay certeza de que sus aspiraciones se concreten. Según el Informe del PNUD, los niveles de seguridad varían enormemente según el tipo de establecimiento al que se asiste, y solamente en la población de nivel socioeconómico alto existe convencimiento de que la educación recibida asegura un buen futuro (PNUD, 1998). Por eso es que entre los estudiantes que pertenecen al sistema municipalizado sea más frecuente aspirar solamente a completar los estudios secundarios y entrar inmediatamente al mundo del trabajo ${ }^{4}$.

En este sentido, si hay una realidad que logra representar los dilemas que enfrenta el conjunto de la educación, es la que vive el sistema municipalizado. Por este conjunto de motivos, el propósito del texto se concentra en la población joven que asiste solo a este tipo de establecimientos, para indagar sobre las miradas que elaboran respecto a la educación, sobre sus posturas frente a los discursos que sobre ella circulan. ¿Está en la educación el futuro realmente?, ¿son los estudios el camino? Las posibles respuestas solo las pueden dar los estudiantes, pues ellos son -a fin de cuentas- quienes viven, desde dentro, la vorágine de dilemas que bordean a la educación.

\section{Transiciones y trayectorias}

\subsection{Estructuras de transición}

Para el enfoque de las transiciones a la vida adulta, la juventud representa un período intermedio que es paso y, a la vez, espera entre dos estados: entre la infancia y la adultez, que son el antes y el después, se encuentra la juventud, que es todo lo que comprende el paso de una a otra. Ser joven es ir dejando de ser niño sin aún

4 Los datos que entrega la encuesta del cIDE señalan que mientras el porcentaje que piensa ingresar al mundo del trabajo inmediatamente después de terminado el ciclo secundario representa al 3,3\% de los estudiantes del sistema privado y al 7,1\% del subvencionado, entre los que asisten al municipalizado esa proporción llega al 11,7\% (CIDE, 2003). 
De los herederos a los desheredados Juventud, capital escolar y trayectorias de vida - O. Dávila, F. Ghiardo

llegar a ser adulto, estar expuesto a la vivencia de lo indefinido, a la tensión por el desajuste que se produce cuando se deja de ser lo que se era, cuando se altera la identidad que había entre cuerpo, mente y condición social.

Que la juventud represente un período de transición no significa que sea una etapa de pura latencia, de espera inerte, de moratoria inactiva. Por el contrario, toda transición es un proceso lleno de cambios en que hay algo que está en curso, que se desarrolla, que se desenvuelve $y$, si hay algo que define a la juventud como etapa de la vida, es la ocurrencia de cambios inscritos en el cuerpo de un sujeto. Los de orden biológico preparan su inicio y los de condición van marcando el ritmo a un proceso complejo que solo se produce porque los jóvenes actúan, porque son sujetos en tránsito, no en trance. En efecto, ser joven no es siempre ni solamente estar en una fase de preparación, en una «sala de espera», como diría Machado Pais, en que la vida transcurre entre los estudios y el ocio. Mientras se es joven, estadísticamente joven, ocurren hitos que marcan de por vida, muchos se convierten en padres o madres, trabajan, se hacen independientes; todos estos cambios que, en su secuencia, en su orden y en sus tiempos, configuran diferentes formas de «hacerse adulto», diferentes estructuras de transición.

La estructura de las transiciones tiene un carácter histórico. La edad y las formas de hacerse adulto presentan variaciones que dependen de lo que cultural y socialmente se define para cada clase de edad y para cada sexo en cada clase de edad. No siempre se ha seguido estudios ni permanecido en el hogar de origen por tantos años como en la actualidad. Tampoco quienes son madres han alternado siempre entre trabajo, estudios y maternidad. Si por algo existe interés en analizar las transiciones juveniles es porque las formas de transición, hasta hace poco «típicas», han ido cambiando o ya no son las únicas ${ }^{5}$. La tradicional estructura lineal de

5 El cambio en las formas típicas de transición es lo que está detrás del interés por estudiar las transiciones juveniles en Europa, fenómeno que sin duda se vincula con la retirada del Estado de Bienestar como organización social, de las transformaciones al sistema productivo europeo y la migración como fenómeno sociocultural. 
transición, definida por una secuencia culturalmente establecida y socialmente reproducida, en que de estudiar se pasa a trabajar, de ahí al matrimonio y la crianza de hijos, todo con plazos estrictos, con edades prescritas, ha ido cediendo terreno a nuevas formas de hacerse adulto, nuevas formas de transición, con otra estructura, con otro orden en la secuencia y otros tiempos para cada paso.

Que la estructura de las transiciones tenga un carácter histórico no quiere decir que cada época genere un solo modo de hacerse adulto común para todos. Por el contrario, en cada época hay diferentes «libretos» para las transiciones, cada uno característico de un grupo social específico ${ }^{6}$, y de lo que cada grupo asigna a cada género. Las diferencias tienen que ver tanto con el tipo de etapas por las que se pasa como con los tiempos cronológicos en que ocurre un mismo cambio de condición. Las etapas por las que han pasado las generaciones de jóvenes de los distintos grupos sociales han sido diferentes. No siempre los jóvenes de sectores populares han estudiado, luego trabajado y conformado familia. Hasta no hace mucho, el paso de la infancia a la adultez era para ellos un paso corto, drástico, trabajaban desde temprana edad, sin estudios o con muy pocos. Situación quizás más marcada en las mujeres, que pasaban de ser niñas a esposas y madres, sin etapas intermedias.

En la actualidad, la ampliación de la cobertura del sistema escolar permite que jóvenes de grupos sociales diferentes puedan pasar por las mismas etapas, ordenadas de la misma forma, pasar

6 La «juventud dorada» de mediados del ochocientos, por ejemplo, «maduraba siguiendo paso a paso un libreto trazado de antemano, que era rígido pero seguro y, en todo caso, asaz conspicuo: una operación universitaria local tipo relámpago destinada a obtener un título profesional, uno o varios viajes a Europa, casamiento ventajoso allá o acá, retorno a Chile para hacerse cargo de los grandes negocios de la familia, y, finalmente, asunción de la adultez ingresando a la política de nivel nacional, ojalá como 'senador' o 'ministro'» (Salazar y Pinto, 2002:31). Mientras, en la misma época, los jóvenes gañanes vivían otras experiencias, se hacían adultos de otra forma, yéndose adolescentes del hogar en busca de suerte por los caminos, adoptando el vagabundaje como forma de vida, en permanente movimiento, trabajando un tiempo en un lado y luego en otro, probando suerte, a veces robando, seguros de que nada era seguro, con pocas o ninguna posibilidad de formar un hogar, de establecer familia (Salazar y Pinto, 2002). 
De los herederos a los desheredados Juventud, capital escolar y trayectorias de vida - O. Dávila, F. Ghiardo

de los estudios al trabajo y de ahí a la formación de familia, todos siguiendo la misma secuencia. Sin embargo, hay diferencias en los tiempos de duración que se asignan a cada etapa, las edades en que se produce cada paso. Por lo general, los jóvenes de bajos recursos económicos estudian menos años y entran a trabajar a edades más tempranas que los de clases media y alta. Como contrapartida, la edad hasta la que estudian los jóvenes de clases media y alta es mayor que la de jóvenes de clase baja. Con todo esto, el tiempo se vuelve un factor central para el análisis de las transiciones. No incluirlo significa dejar fuera un elemento generador de estructuras de transición diferentes tanto entre períodos históricos como entre grupos o clases sociales.

Cualquier cambio histórico en la forma de las transiciones es producto y a la vez produce una forma de concebir el tiempo, de situarse en la relación entre presente y futuro, que se expresa de manera suma en la etapa de la juventud. En efecto, la vivencia de la juventud sitúa al futuro en un lugar central. Siempre da vueltas en la memoria y la imaginación, incluso del que dice vivir solo el presente. Cuando se es joven, socialmente joven, la familia, el Estado, la escuela, la sociedad, fuerzan la definición del futuro, otorgan la facultad para elaborar proyectos de vida y asignan tiempo para realizarlos. La juventud se impone como la etapa en que se debe definir el futuro, en que los sueños de la infancia se vienen encima, se vuelven problema del presente. Disposición social que la convención convierte en convicción, que cuando se hace subjetiva estimula la proyección presente de la vida futura y despierta anhelos sobre lo que se quisiera hacer y llegar a ser, sobre el mundo que se quisiera vivir. Sueños sobre el futuro que forman parte de un proceso íntimo, profundamente personal, cuya fuente no está, sin embargo, puesta en el vacío, fuera de toda conexión con la realidad (PNUD, 1998). Por el contrario, las aspiraciones nacen de condiciones sociales, de los «mundos de vida» que configuran esas condiciones; se nutren de cuentos que se han escuchado, de historias familiares, conocidas, de lo que le pasó al amigo, lo que llegó a ser el conocido, lo que tuvo que ha- 
cer el familiar para «ser lo que es» 0 «tener lo que tiene». Ahí está la fuente y a la vez el filtro de esos sueños, el fondo de experiencia que contrasta lo ideal con lo posible, que convierte la aspiración en expectativa ${ }^{7}$. Esa forma de ver y enfrentar la realidad que se crea en vida, con lo que a cada uno le toca vivir, condiciona los futuros posibles de ser pensados y abre o cierra las posibilidades para llevarlos a cabo. Y en este juego, entre presente y futuro, entre sueños y decisiones, entre lo ideal y lo posible, los jóvenes se van haciendo adultos y ocupando un lugar en la sociedad, configurando su transición y trazando una trayectoria.

\subsection{Transición y trayectoria}

La diferencia entre transición y trayectoria no ha estado siempre del todo clara: se suele identificar ambos términos y utilizarlos para designar el mismo fenómeno. Machado Pais, por ejemplo, llama yo-yo a la estructura de transición que va y vuelve de una condición a otra, del estudiante que pasa al trabajo y luego vuelve a ser estudiante, o del dependiente que pasa a la independencia y luego vuelve a la dependencia. Pese a esto, transición y trayectoria son fenómenos diferentes. La transición es un proceso inevitable, común a todo individuo y presente en todo momento histórico. Siempre y en todo lugar, los niños crecen, se convierten en adultos, más allá de lo que social y culturalmente signifique ser adulto, de lo que haga adulto, de los signos y ritos que marquen el paso de una a otra etapa, de la edad que señale la mayoría de edad. Que en tiempos modernos se le llame «juventud» a este período de paso, que su extensión, sus etapas y su estructura sean diferentes a las de cualquier otra época y forma de sociedad, son fenómenos que responden a procesos sociales, culturales, históricos que, sin embargo, no niegan su ocurrencia.

7 «Aspiraciones, anhelos, sueños, son las representaciones que se hacen los individuos y los grupos acerca del estado de cosas, personales o sociales, que desean para el futuro y que caracterizan como 'lo mejor'. Las aspiraciones son distintas de las expectativas, porque éstas se refieren a lo que se cree que ocurrirá en el futuro dadas las tendencias actuales, no lo que se desea que ocurra ni lo que se está dispuesto a hacer para ello» (PNUD, 1998:58). 
De los herederos a los desheredados Juventud, capital escolar y trayectorias de vida - O. Dávila, F. Ghiardo

La trayectoria está puesta en otro plano, en el plano social, de las posiciones que van ocupando los sujetos en la estructura social o, lo que es igual, en el campo de las relaciones de poder entre los grupos sociales. No es la secuencia que producen las distintas «fases» de generación de nuevos «individuos adultos» lo que importa al análisis de trayectorias, sino las posiciones estructurales y las disposiciones subjetivas que producen -en el doble sentido de ser producto de y de producir- esos cambios de condición. Si, para el análisis de las transiciones el paso de estudiante a trabajador importa en sí mismo, si la edad en que se produce es un factor que influye en la descripción de la estructura de las transiciones, para las trayectorias importan el grupo social de origen, el nivel de educación alcanzado, el tipo de establecimiento escolar, el título y el tipo de trabajo al que se accede con ese título, la valoración social y simbólica del título obtenido.

Aunque las transiciones y las trayectorias estén en planos diferentes, no son procesos que permanezcan indiferentes. Entre la estructura de las transiciones y la forma de las trayectorias existe una implicación que es mutua, con múltiples conexiones, influencias que van y vienen y que los convierten en procesos que solo se entienden en su relación, en su mutua implicancia. Los cambios en la estructura de las transiciones, que definen los cambios en la extensión y el significado mismo de la palabra juventud, no se pueden comprender sin incorporar al análisis la trayectoria del grupo o la clase de la cual esa estructura de transición es característica o típica en un momento histórico acotado. Las trayectorias son, en efecto, factores que marcan las estructuras de transición. Que en la actualidad los jóvenes estudien más años que en épocas anteriores constituye un fenómeno que ha cambiado la estructura de las transiciones y que solo se entiende como expresión práctica de una estrategia, de una disposición orientada a asegurar el futuro, una posición futura invirtiendo en educación; que permanezcan en sus hogares hasta edades más avanzadas, incluso más allá del límite estadístico o convencional de la juventud, forma parte de estrategias o medidas forzosas para 
enfrentar fenómenos estructurales sin perder la posición en esa estructura; que las mujeres retrasen la maternidad o que, siendo madres, alternen ese «rol» con el de estudiante y de trabajadora, tiene un claro nexo con disposiciones prácticas que apuntan a la búsqueda de unas condiciones de vida, de una posición social difíciles de alcanzar con la maternidad y la inactividad.

La estructura de las transiciones, sobre todo en lo que toca al factor temporal, cronológico, constituye un elemento que influye en las trayectorias. Ser madre o padre a temprana edad, por ejemplo, no es solamente un cambio de condición que puede arrastrar consigo otros cambios de condición anexos, pasar de la dependencia a la independencia o de la inactividad a la actividad, sino también producir efectos sobre las trayectorias, limitando los años de estudio y el abanico de oficios a los que se puede acceder con esos años de estudio y condicionando, en definitiva, las posibilidades de trayectoria, la posición posible de ser ocupada en la estructura social.

El efecto que ejerce una estructura de transición sobre la trayectoria es relativo y pasa por el grupo social de pertenencia. Los diferentes pasos que conforman una estructura de transición tienen efectos diferentes que dependen de las condiciones en que se producen esos pasos. Por ejemplo, dos mujeres pueden seguir una transición idéntica en su estructura, ser madres a una misma edad y las dos dejar de estudiar a un mismo tiempo; sin embargo, lo que signifique la maternidad para una y otra será diferente dependiendo de su posición en la estructura social, si una es hija del gerente de una empresa y la otra hija de un albañil de la construcción. La estructura de la transición puede ser la misma, con los mismos cambios de condición en un mismo orden y a un mismo tiempo, pero las condiciones en que transcurren esos tránsitos, y lo que se puede llamar el efecto o el «impacto» de esos cambios de condición sobre los futuros posibles para cada caso son diferentes y dependen de las condiciones de origen o, si se quiere, de las condiciones de clase. 
De los herederos a los desheredados Juventud, capital escolar y trayectorias de vida - O. Dávila, F. Ghiardo

Casos posibles hay muchos. Lo que queremos destacar es que la transición y la trayectoria constituyen dos aspectos que son fundamentales en la generación de los diferentes sujetos juveniles. En su relación, se puede ir tejiendo la madeja que permite comprender, si no totalmente, al menos en forma parcial, la configuración de prácticas, la creación de aspiraciones, la formulación de expectativas y el despliegue de las diferentes estrategias que adoptan los jóvenes. Relación, por cierto, compleja, que pone el análisis frente a un tema difícil: la relación entre estructuras sociales, formaciones culturales y lógicas -o sentidos- de la acción.

\subsection{El espacio de las trayectorias}

Para pensar en términos de trayectorias, tenemos que partir suponiendo que la trayectoria social de cada individuo puede ser representada como una curva inscrita en un espacio. No se trata, en todo caso, del espacio físico por donde los individuos se mueven, actúan, donde ocurren los fenómenos de la vida social. Este plano de cosas se da por supuesto, tiene que existir, pero el espacio de las trayectorias sociales no es «el mundo» ni «la ciudad».

La referencia que aclara en qué consiste un espacio de este tipo es la noción de espacio social que desarrolla Bourdieu. En La distinción, el sociólogo francés intenta introducir dimensiones que hasta entonces habían quedado fuera del análisis de las clases sociales, más concentrado en construcciones teóricas y presupuestos ideológicos, y desarrollar un análisis que llevara el tema al terreno de las prácticas y las tomas de posición. La idea de fondo es que, si hay algún criterio que puede actuar como principio conformador de grupos sociales, ese se encuentra en el terreno de las prácticas sociales mismas y de las disposiciones subjetivas que las generan. A partir de ese supuesto, Bourdieu realiza un análisis complejo, con referencias a fuentes primarias y a estudios propios, que le permiten ir estableciendo relaciones entre una multiplicidad de prácticas -deportes, juegos de salón, visitas a 
museos, preferencias musicales y plásticas, opinión política- con las características que definen a cada «agente» individual, como los llama Bourdieu, su nivel de educación, el tipo de establecimiento del que egresó, el título que posee, la actividad que desarrolla, si es campesino, obrero calificado, profesional, académico, empresario, el campo de contactos que posee...

El resultado es lo que Bourdieu define como espacio social; un cuadro gráfico en tres dimensiones formadas por el cruce de dos ejes, cada uno escalado de más a menos: uno horizontal con dos dimensiones que corresponden al capital económico y al capital cultural, y otro vertical que representa la suma de los diferentes tipos de capital -cultural, económico, social, político, simbólico-, lo que Bourdieu define como volumen global de capital. Cruzando estos ejes, aparecen los distintos cuadrantes de posición, diferenciados según concentren mayores o menores niveles de capital económico y cultural, por un lado, y de capital global, por el otro.

En este plano, cada individuo ocupa un punto cuyas «cOordenadas» se obtienen aplicando una función que desglosa la estructura de su capital, esto es, mide el volumen de cada especie de capital y los ordena de acuerdo a su peso relativo. Las diferencias de posición entre un individuo y otro quedan, de este modo, determinadas por el volumen de capital que posee -sobre todo del económico y el cultural- y por la estructura de esos capitales. Así, por ejemplo, dos agentes que están ubicados en posiciones muy distantes en la distribución del ingreso (capital económico) y con niveles de educación (capital cultural) muy diferentes, que pueden corresponder a un obrero de la construcción o un comerciante ambulante el primero, y a un ingeniero o un médico, el segundo, se ubican en cuadrantes diferentes porque poseen volúmenes de capitales muy diferentes. Ahora bien, dos agentes pueden tener igual volumen de capital global y aún así ocupar posiciones diferentes dependiendo de que el capital con mayor peso relativo en su estructura sea el económico -un empresario, por ejemplo- o el cultural -un académico-. 
De los herederos a los desheredados Juventud, capital escolar y trayectorias de vida - O. Dávila, F. Ghiardo

$\mathrm{Al}$ ir ubicando a los individuos en este espacio, es inevitable que se comiencen a producir relaciones de cercanía que terminen generando grupos de posición o «nubes de puntos» que concentran en una posición distinguible a todos aquellos que presentan un volumen y una estructura de capitales similares. Cada grupo de posición aparece asociado, también por relaciones de cercanía/lejanía, con una serie de prácticas, opiniones, gustos, y, en la medida que se acercan a otros grupos de posiciones, se van generando clases de posiciones diferenciadas por su ubicación en la estructura de distribución de los distintos tipos de capital y por el tipo de disposiciones prácticas que adoptan.

Todo esto hace que el espacio social que elabora Bourdieu sea fundamentalmente un espacio de relaciones. En él, las distintas posiciones y los distintos grupos de posiciones adquieren significado en su relación con otras posiciones y otros grupos de posición. Solo al verlos en su «exterioridad mutua», en su cercanía o lejanía, vecindad o alejamiento, en su orden (arriba, abajo, entre), los grupos de posiciones se convierten en grupos sociales con características y prácticas comunes, con «estilos de vida» que tienden a ser similares entre quienes conforman un grupo y diferentes entre uno y otro grupo. En el espacio social, dice Bourdieu, «los agentes tienen tantas más cosas en común cuanto más próximos están en ambas dimensiones y tantas menos cuanto más alejados. Las distancias espaciales en el papel equivalen a distancias sociales» (Bourdieu, 1997:18). Por extensión, el espacio social opera también como una matriz de probabilidades: permite prever, siempre parcialmente, cosas probables que ocurran; decir, por ejemplo, que personas con un mismo nivel de educación, que tienen un nivel de ingreso parecido, que asisten a los mismos lugares y con la misma frecuencia, que consumen una misma gama de bienes y los pagan de una misma forma, es mucho más probable que actúen y tengan posturas parecidas entre sí y diferentes a las de quienes, en un momento determinado, no tienen lo que ellos tienen, ni hacen lo que ellos hacen. De ahí que el espacio social represente las diferencias entre las prácticas y las 
tomas de posición, entre las formas de vida y las formas de «ver el mundo» que adoptan los distintos grupos sociales. Por eso, también Bourdieu insiste en que, más que teórica, las clases sociales tienen primero una base estadística: solo en la medida que existan grupos de individuos con características similares, existe, al menos en potencia, la formación de clases sociales con sentido de acción histórica.

A través de este mecanismo de posicionamiento, Bourdieu logra representar la estructura de una sociedad, las relaciones que se establecen entre los diferentes grupos y las diferentes clases que la componen, relaciones que pasan por la posición que ocupa cada grupo o clase en la distribución de los distintos tipos de capital y que no expresan sino relaciones de poder. Aunque esas relaciones se expresen en las distintas dimensiones de la vida social, aunque los diferentes tipos de capital -cultural, económico, social-y los respectivos subcapitales -lingüístico, escolar, simbólico, político- están, en la práctica, en una relación de implicación mutua, que el capital económico y el cultural formen el eje principal de este espacio es una arbitrariedad que tiene sus fundamentos. La razón es simple: si se trata de conformar grupos sociales, hay que partir de los factores que más gravitan en la estructuración de las sociedades, los que con más fuerza determinan la generación de diferencias entre los grupos sociales, que más condicionan las condiciones de vida y que, a la vez, más condicionan la forma en que cada individuo o grupo interpreta esas diferencias.

Este último punto es fundamental para el esquema de análisis que plantea Bourdieu, pues, para que el espacio social produzca diferencias, para que esas diferencias operen en la práctica, tienen que ser reproducidas por cada miembro de los diferentes grupos. Las diferencias sociales tienen una base objetiva -se expresan, por ejemplo, en el tamaño, la ubicación y los materiales de la vivienda, el nivel de educación, de ingresos, el tipo de bienes de consumo a los que se tiene acceso con ese ingreso-, pero 
De los herederos a los desheredados Juventud, capital escolar y trayectorias de vida - O. Dávila, F. Ghiardo

ellas solo operan como diferencias sociales porque están inscritas en un «sistema simbólico» que permite «captar» la diferencia. Como señala Bourdieu, «una diferencia, una propiedad distintiva [...] solo se convierte en diferencia visible, perceptible y no indiferente, socialmente pertinente, si es percibida por alguien que sea capaz de establecer la diferencia -porque, estando inscrito en el espacio en cuestión, no es indiferente y está dotado de categorías de percepción, de esquemas clasificatorios, de un gusto, que le permiten establecer diferencias, discernir, distinguir-» (Bourdieu, 1997:21). Un cóctel de atún con mayonesa y otro de caviar, un Mercedes Benz y un sedán coreano, escuchar a Mozart o a Juan Gabriel, jugar al polo o al fútbol, solo producen distinción porque cada agente los reconoce y los interpreta, porque esos bienes, esas prácticas, esas preferencias operan como signos sociales que producen distinción. El espacio social opera como el lenguaje, que es posible solo porque las palabras son interpretadas por una «comunidad de hablantes».

Estos esquemas de interpretación -que Bourdieu llama habitus-varían dependiendo de la posición que se ocupe en el espacio social. «A cada clase de posición corresponde una clase de habitus (o de aficiones) producidos por los condicionamientos sociales asociados a la condición correspondiente» (Bourdieu, 1997:19). Desde cada posición, se produce una «forma de mirar» que filtra el significado de un «signo» y le da sentido. Ya se trate de una práctica, un bien de consumo, un gesto, una comida o la forma de comerla, depende del habitus su sentido, si es bueno o malo, bello o feo, vulgar o distinguido. Esquemas que se mantienen en la medida que permanecen como bienes o prácticas propios de una clase y que van variando en la medida que cambia su forma de distribución. Como el caso del boxeo que expone Bourdieu, que, de ser práctica exclusiva de las clases altas, signo de distinción que distinguía a sus practicantes, se convierte en deporte vulgar cuando comienza a ser practicado por miembros de las clases más bajas. 
Así como el sentido de la distinción es relativo a la forma en que se distribuyen los grupos sociales, la distribución misma de esas posiciones representadas en el espacio corresponde a una fracción acotada de tiempo. La posición de cada agente, su cercanía o distancia con otros, la formación de grupos con prácticas, consumos, gustos, opiniones parecidas o diferentes, reflejan una situación que es de momento; pero eso no significa, en todo caso, que responda a designios del azar. Por el contrario, ocupar una posición determinada, poseer más o menos volumen de capital, estar «arriba» o «abajo» en la estructura social, es la expresión presente de posiciones históricas, de una trayectoria formada por «ascensos»y «descensos», aumento y disminución de capitales, resumen de las posiciones en que se ha jugado en los distintos campos de juego, en los distintos ámbitos en que se disputan los capitales.

Esto es lo que le da al espacio social un carácter histórico, el hecho que los capitales sean elementos en disputa. Los distintos grupos sociales compiten por su apropiación en distintos campos, cada uno con su propia estructura, con grupos mejor y peor posicionados, con tipos de capitales o subcapitales de mayor peso en la definición de las posiciones que definen su estructura. En el campo del arte, por ejemplo, al que Bourdieu dedica particular atención, los que exponen en museos importantes, portadores del arte académico, legítimo, casi siempre los más viejos, de mayor trayectoria y que venden caro su obra, están mejor posicionados que los que cultivan un arte heterodoxo, casi siempre los más jóvenes, que exponen en galerías pequeñas o venden sus cuadros personalmente y a bajo precio, casi para la subsistencia. $\mathrm{O}$, en el campo de la economía, quizás el más conocido y más analizado, con los grandes empresarios y los obreros como sujetos representativos de las diferencias de posición, grupos con volúmenes diferentes de capital; reflejo, en definitiva, de un proceso histórico, observable en la trayectoria del grupo, que condensa en un punto las distintas posiciones que ha ocupado en las disputas 
De los herederos a los desheredados Juventud, capital escolar y trayectorias de vida - O. Dávila, F. Ghiardo

por la acumulación de los distintos tipos de capital. Posición que no es, en todo caso, fija, inalterable; por el contrario, un grupo o una clase puede ir cambiando su posición, mejorar o empeorar su lugar en la disputa por los capitales de uno o varios campos a la vez, cambiando, con eso también, la estructura de esos campos o del espacio social en su conjunto.

\section{Trayectos y proyectos de vida juvenil}

\subsection{Metas educacionales}

La sociedad chilena viene experimentando un acelerado proceso de expansión y ampliación de sus coberturas escolares durante la última década, presentando en la actualidad una cobertura universal en la enseñanza primaria, superior al 93\% en la enseñanza secundaria, y alrededor del 37\% en la educación superior; tendencia sobre todo en la enseñanza superior que aún tiene posibilidades de crecimiento, proyectándose que, hacia fines de la década, habrá en el sistema de enseñanza superior del orden de un millón de estudiantes que representarían una proporción cercana al 50\% de la población joven en edad de estudios superiores, distribuidos muy desigualmente de acuerdo a su situación socieconómica.

Con la expansión del acceso a la educación, incluso con bajos índices de deserción escolar primaria y secundaria, y el aumento de los años de escolaridad en la población joven y general, como también la disminución del peso poblacional del segmento joven, fruto de variables sociodemográficas y de transición demográfica en curso en la sociedad chilena, se hacen pertinentes las perspectivas que asocian a la actual población juvenil con un aumento en sus metas, expectativas y aspiraciones vinculadas a la educación. Estaríamos en presencia de una nueva revolución de expectativas y metas, principalmente de tipo educacional.

La política pública educacional, a través de los procesos de reforma educacional de los últimos quince años, no solo ha insta- 
lado y desplegado diferentes instrumentos y herramientas en esa dirección, sino que también ha logrado instalar y convenir un discurso social que abarca a todos los agentes y actores involucrados en el proceso, con un carácter de discurso único y hegemónico sobre la importancia de la educación como factor de igualdad de oportunidades sociales y posible corrector de desigualdades en la estructura de oportunidades inequitativas. Posiblemente, estos discursos consensuados y aceptados socialmente pueden constituirse en una situación peculiar en la sociedad contemporánea: el alto grado de aceptación y legitimidad con que cuenta, no existiendo caminos ni discursos alternativos en el tránsito propuesto por la política educativa como impulso a los desafíos y tareas del desarrollo del país.

El punto pendiente en esta argumentación y lineamientos de política está ubicado en ciertos intersticios -no menos importantes- pero que se inscriben dentro de los discursos que relevan la educación como motor y freno de inequidades y desigual distribución de las oportunidades sociales. Estas, en menor medida, se vinculan con las coberturas educacionales (básica y media; pero sí en la superior), sino la calidad de la educación que se imparte en los diferentes subsistemas, con una clara configuración acorde con las estratificaciones sociales, culturales y económicas de los alumnos y sus familias.

Los ejes de interrogación en esta línea van encaminados a examinar y analizar sobre los roles sociales que cumplen o debieran cumplir la educación y la escuela, preguntándose sobre la efectividad y eficiencia que presentarían la educación y la escuela como igualadoras en la estructura de oportunidades (tanto en el acceso, permanencia, como egreso), o si sencillamente está ajustándose a las premisas clásicas de la diferenciación social: el reproducir y profundizar las desigualdades de entrada o de inicio, sobre la base de los capitales con que cuentan dichos sujetos y sus familias, configurando un efecto de destino natural (cfr. Bourdieu, 1998). Y desde el punto de vista de las orientaciones de 
De los herederos a los desheredados Juventud, capital escolar y trayectorias de vida - O. Dávila, F. Ghiardo

la política educacional y su expresión programática en la dirección de avanzar en la «igualdad de oportunidades para aprender», es preciso examinar las condicionantes que han impedido avanzar en la equidad educativa, que relega a los estudiantes de menores ingresos a posiciones sociales desmejoradas: en acceso como en calidad (OCDE, 2004).

Las posibilidades de logro o equiparación de aquellas orientaciones de la política educativa, en orden a la mejoría de posiciones sociales por parte de los sujetos en desventaja en su trayectoria educacional y de vida, muestra su efectividad con rezago en el tiempo, pero sin duda existen condicionantes o aspectos favorables para enfrentar su análisis con un carácter prospectivo. Las trayectorias de vida de los jóvenes estudiantes se constituyen, por su vivencia pasada, presente y sus perspectivas de futuro, expresadas en el plano de las metas, motivaciones, expectativas, aspiraciones y conformación de proyecto de vida.

Las dimensiones en que opera el factor educativo van configurándose en torno a órdenes de tipo estructural y macrosocial, teniendo como horizonte el garantizar una integración funcional para estos jóvenes, principalmente por la vía de velar por el acceso y calidad de su inserción educacional y la preparación -con estos capitales escolares- para su inserción sociolaboral en un futuro cercano. Ese contexto y dinámica nos remiten a la dimensión más estructural de la integración social; sin embargo, cada vez y con mayor fuerza, también debe considerarse la dimensión subjetiva de los sujetos, expresada en las múltiples significaciones, diálogos y percepciones que establecen aquellos con la dimensión estructural, sobre sí mismos y otros similares, como con los diferentes actores intervinientes en sus cursos escolares y trayectorias de vida. Para esto, se requiere plantear, en ese contexto entre lo estructural y lo subjetivo, cómo se vinculan y trazan conexiones entre ambas dimensiones, a partir desde los propios sujetos (cfr. INJUV, 2004). 
Desde una perspectiva general, que pone en discusión aquellas dimensiones, vemos la confirmación de la tensión existente desde los jóvenes y estudiantes en cuanto al optimismo frente al futuro, versus las posibilidades reales de concreción de sus proyectos futuros, lo que nos lleva al terreno de las oportunidades sociales que perciben los jóvenes como posibles de acceder.

De aquí, podemos apreciar que entre quienes se sienten «muy optimistas» $\mathrm{u}$ «optimistas» sobre su futuro son un $92 \%$ de los jóvenes consultados, con una muy baja ponderación entre los que expresan un sentimiento de pesimismo. Esta visión optimista del futuro por parte de los jóvenes ha sido una constante en los estudios sobre juventud en los últimos tiempos. En un sondeo nacional, sobre 32 mil estudiantes secundarios de establecimientos con subvención estatal (municipales y particular subvencionados), ante esta misma formulación, entre los «muy optimistas» y «optimistas» sobre su futuro, sube levemente al 94,6\% de los entrevistados (Oyarzún e Irrazabal, 2006).

Con una formulación similar, pero incorporando una dimensión de temporalidad, en la cuarta encuesta nacional de juventud 2003 del Instituto Nacional de la Juventud de Chile, ante la consulta «cómo crees que vas a estar en cinco años más», quienes señalan que estarán «mejor que ahora» se alcanza un total de $84,7 \%$ de los encuestados entre 15 y 29 años de edad. De acuerdo a esta fuente, los jóvenes tienen una imagen mucho mejor en su situación personal en el tiempo, que la imagen que tienen del país en el mismo período de tiempo propuesto, donde los consideran que «Chile va estar en cinco años mejor que ahora» son un $49,1 \%$ del total.

Puestos en tiempo presente, sobre los niveles de agrado con su vida actual, se aprecia similar situación a la descrita más arriba. Quienes se sienten «muy contentos» y «contentos» con su vida actual, se alcanza el 89,7\% de los jóvenes; cifra agregada exactamente igual al sondeo nacional referenciado (Oyarzún e 
De los herederos a los desheredados Juventud, capital escolar y trayectorias de vida - O. Dávila, F. Ghiardo

Irrazabal, 2006). La tensión señalada entre el optimismo de los jóvenes sobre su futuro y las posibilidades de concreción de sus proyectos se ve reflejada en que más de la mitad de ellos (52,5\%) considera que sus posibilidades son «pocas» $(47,6 \%)$ o «ninguna» $(4,9 \%)$, y menos de un tercio las califica como de «muchas» $(29,6 \%)$. Quienes no lo tienen aún claro alcanzan el $17,9 \%$ y principalmente corresponden a los estudiantes de menor edad. Los jóvenes que se sienten con muchas posibilidades de realizar sus proyectos, en mayor medida tienen un sentimiento de optimismo ante el futuro, situación que incluso alcanza a un amplio porcentaje de quienes se perciben con pocas posibilidades de concretar sus proyectos.

En el contexto del optimismo sobre el futuro de estos jóvenes, no es de extrañar que eso se relacione con una ampliación de las metas que se fijan en el presente y hacia el futuro. De manera particular, lo podemos apreciar en cuanto a las metas educacionales que desean alcanzar; donde dos de cada tres estudiantes se plantean, en el plano educacional, como mayor meta, el proseguir estudios postsecundarios $(66,6 \%)$, desagregados en las modalidades de centro de formación técnica (CFT) (5,2\%), instituto profesional (IP) (14,7\%) e ingreso a la universidad (46,7\%). Las otras opciones corresponden a completar la enseñanza secundaria $(21,5 \%)$, con fuerte presencia de quienes recién inician este nivel educativo y de menores edades; y la opción de no tener clara aún su mayor meta educacional (12\%).

Ya se ha señalado la influencia de las escolaridades de la madre y el padre o el clima educacional en el hogar, que ejerce sobre un conjunto de dimensiones vinculadas con las aspiraciones, expectativas, metas escolares y configuración de proyectos futuros en los jóvenes, donde se visualiza con claridad la tendencia a aumentar las metas en el plano escolar a medida que sube la escolaridad del padre y de la madre, y de manera especial y significativa en el caso de la madre. Es así cómo la alternativa de ingreso a la universidad muestra las diferencias más significativas con una 
tendencia al aumento del porcentaje de casos que se ubican en esta opción conforme aumenta el nivel de escolaridad de la madre. Va del $36,5 \%$ de los casos con madres que no completaron la enseñanza básica, al 66,1\% de las que se titularon de una profesión.

En cuanto a la relación entre las posibilidades de concreción de sus proyectos y la mayor meta educacional, vistos por grupos, el más numeroso señala tener muchas posibilidades en el Chile actual, aspira a ingresar a un centro de formación técnica (36,6\%). Con 33\%, le sigue el grupo que pretende ingresar a un instituto profesional y con 30,5\% el que quiere entrar a la universidad. Esto es, que entre quienes aspiran continuar estudios, la percepción de las posibilidades reales es mayor mientras más bajo es el nivel de escolaridad al que se aspira.

La sensación más frecuente en todos los grupos es que sus posibilidades son pocas. Los porcentajes aumentan en la medida que es mayor el nivel de escolaridad al que se aspira. La mayor proporción de casos se da entre quienes aspiran ingresar a la universidad (50,3\%), de grandes aspiraciones, pero pocas posibilidades, seguido de los que quieren acceder a un instituto profesional $(47,9 \%)$, a un CFT $(46,3 \%)$, quienes no tienen claro su proyecto $(44,8 \%)$ y, al final, quienes quieren completar la enseñanza media $(44,2 \%)$.

Estas altas metas en lo educacional, pero con pocas posibilidades, por la vía de proseguir estudios superiores, dista de ajustarse a las actuales posibilidades de acceso y cobertura de este nivel educativo, donde la cobertura alcanza al 37,5\% como conjunto del sistema, muy desigualmente distribuido de acuerdo a condiciones socioeconómicas y establecimientos de procedencia de la enseñanza secundaria. De acuerdo a la tercera encuesta nacional de juventud (2000), el destino escolar de los jóvenes que completaron la enseñanza secundaria, según la dependencia administrativa de los establecimientos de procedencia, reporta que solo el $16,9 \%$ de los estudiantes de liceos municipalizados se encontraban en el sistema de educación superior, desagregados en un $12,7 \%$ en universidades e institutos profesionales, y un $4,2 \%$ 
De los herederos a los desheredados Juventud, capital escolar y trayectorias de vida - O. Dávila, F. Ghiardo

en la modalidad de estudios técnicos superiores. Para la enseñanza particular subvencionada, el total en la educación superior es del 28,6\%; y, para la educación pagada como procedencia, es del $52,4 \%$ de estudiantes de educación superior (INJUV, 2002).

Esto es solo un antecedente dentro del sistema de selección e ingreso a la enseñanza superior denominada pública, excluyéndose para las predicciones de ingreso a la enseñanza superior por la vía de universidades privadas, ciertos institutos profesionales y los centros de formación técnica, que, en su mayoría, no es factor de exclusión los puntajes obtenidos en las pruebas de selección universitaria. De cualquier modo, aún no hay una construcción desagregada del conjunto del sistema de educación superior que considere no solo la dependencia administrativa de procedencia de sus alumnos, sino que vaya encaminada a precisar y analizar las diferencias de estratificaciones y condiciones socioeconómicas y culturales de su alumnado, en lo que podría equivaler a la auditoría de equidad que plantea el Informe de la OCDE (OCDE, 2004).

Explorando entre los jóvenes sobre las condicionantes y factores que favorecerían la concreción de sus metas educacionales, tanto desde factores y acciones personales, como de contexto y entorno: familiar, el liceo, condición social; aparece en primer lugar el entorno familiar, o el contar con el apoyo de su familia $(43,6 \%)$ como lo más importante para concretar sus metas educacionales, seguido de factores personales como tener esfuerzo y persistencia $(23,9 \%)$, y luego de factores económicos en cuanto a disponer de recursos (12,7\%), y solo en cuarto lugar figura la dimensión del liceo, expresado en una buena preparación por parte de este (10,7\%). La quinta y última opción corresponde al soporte del Estado como la posibilidad del acceso a beneficios estatales de becas y crédito universitario (9,1\%). De las opciones presentadas, las más importantes en la concreción de sus metas educacionales están en el entorno familiar y personal de estos jóvenes, quedando relegadas a un segundo plano las dimensiones más 
institucionales de soporte como sería el liceo y el apoyo estatal en beneficios estudiantiles; al igual que la baja ponderación que asignan estos jóvenes al hecho de disponer de los recursos económicos para solventar la educación superior, teniendo en consideración que con la ampliación de la oferta educativa superior, este es un factor determinante en el acceso a estudios superiores.

En las alternativas de futuro, luego del egreso de la enseñanza secundaria, los jóvenes señalan que, de acuerdo con los conocimientos y habilidades que le entrega el liceo, se encuentran mejor preparados para desempeñarse bien en un trabajo, que entre las opciones agrupadas de «muy preparado» y «preparado» alcanzan un $85,7 \%$, en comparación con estudiar una carrera universitaria $(53,8 \%)$ o estudiar una carrera técnico profesional $(72,1 \%)$. De cualquier manera, las ponderaciones sobre los niveles de preparación que les otorga el liceo, sea para trabajar o estudiar, son altas y denotan una evaluación positiva de los alumnos hacia su liceo y enseñanza en cuanto a su preparación para asumir proyectos de futuro, luego del egreso de la enseñanza secundaria.

Desde el punto de vista de las opiniones y percepciones que expresan los profesores sobre las metas educacionales y proyectos de egreso de sus alumnos, apreciamos diferencias importantes en relación con las de sus alumnos, donde puede destacarse que, según los profesores, la meta que la mayoría de sus alumnos se propone al salir de la enseñanza media es el trabajar (64\%), seguido de estudiar una carrera universitaria $(20,6 \%)$ y, en tercer lugar, estudiar una carrera técnica $(15,4 \%)$. Las diferencias de percepciones son marcadas respecto de las de sus alumnos. No obstante aquellas diferencias, siempre de acuerdo a los profesores, señalan que la tarea del liceo es formar a los alumnos principalmente para que puedan seguir estudiando $(62,3 \%)$ y, en menor medida, formarlos para que puedan trabajar $(37,7 \%)$.

¿A qué pueden deberse estas diferencias de opinión de los profesores entre la percepción de metas sobre sus alumnos y mi- 
De los herederos a los desheredados Juventud, capital escolar y trayectorias de vida - O. Dávila, F. Ghiardo

sión del liceo en cuanto a formación para los proyectos al egreso de sus alumnos? En esta tensión, encontramos una valoración escindida sobre los estudiantes y sus metas y el quehacer del establecimiento donde, en buena medida, se expresa por parte de los profesores una baja expectativa hacia sus alumnos, atribuyendo estas diferencias al sujeto estudiante, entendido como una dificultad para desarrollar la función docente de los profesores, donde señalan que la mayor dificultad para su labor docente corresponde al tipo de alumno con el cual deben trabajar (60,8\%), seguido a larga distancia por la opción del trabajo en equipo para resolver problemas pedagógicos $(15,4 \%)$.

Existe una imagen y determinada caracterología de los estudiantes, por parte de sus profesores, que pareciera estar apoyando o fundando estas percepciones. Incluso los mismos profesores señalan conocer bastante a sus alumnos y entornos socioeconómicos y socioculturales, más allá de sus roles de estudiantes, pero que estarían presentando una serie de sesgos en esta comprensión del sujeto estudiante, relevando en demasía estos entornos por sobre sus desempeños en su oficio de estudiante.

Los profesores, más allá de lo escolar, lo que más conocen de sus estudiantes es el entorno social y cultural de donde provienen $(29,7 \%)$ y, muy asociada a lo anterior, la condición social y económica de su familia (22\%); es decir, más de la mitad de las opiniones sobre conocimiento de sus estudiantes están referidas a dichos entornos, lo que, a nuestro entender, estaría configurando esta imagen desfavorable hacia los sujetos y sus entornos de procedencia. Incluso solo una minoría $(5,1 \%)$ señala que no conoce mucho de sus alumnos.

Este «tipo de alumno con el cual deben trabajar los docentes», de acuerdo a los mismos profesores, presentaría, como problema más característico, situaciones que podemos considerar como de tipo individual (el alumno), de entorno mediato (la familia) y de entorno social (bajos recursos económicos); es decir, varia- 
bles atribuibles al sujeto y su contexto como variables exógenas al proceso de enseñanza/aprendizaje, no figurando de manera relevante variables endógenas de aquel. De estos problemas, según los profesores, el más característico es la desmotivación de los alumnos por los estudios $(33,8 \%)$, la falta de apoyo familiar $(27,1 \%)$ y la carencia de recursos económicos del alumno y su familia (22,7\%). Menores ponderaciones adquieren el deficiente rendimiento escolar $(8,9 \%)$, los problemas de aprendizaje $(3,3 \%)$, las malas relaciones entre los estudiantes $(2,6 \%)$ y la desorientación vocacional $(1,5 \%)$.

Como otra dimensión de la imagen de los profesores sobre sus estudiantes, en cuanto al tipo de alumnos con el cual trabajan, los profesores expresan que solo una minoría (10,3\%) de sus alumnos pueden calificarse como que aprenden fácilmente, y que la gran mayoría $(89,7 \%)$ tienen dificultades para aprender, divididos entre quienes tienen algunas dificultades $(58,6 \%)$ y los que tienen muchas dificultades para aprender $(31,1 \%)$.

La tensión y diferenciación entre el tipo de alumnos y sus entornos, y las tareas educativas de los liceos y sistemas de educación municipal, pueden expresarse, a partir de las percepciones de los profesores, como un sistema de educación municipal que estaría en condiciones de proporcionar una buena educación, pero con otro tipo de alumno. Es así cómo los profesores, en su gran mayoría, catalogan la educación que entrega este sistema entre de alta calidad $(19,7 \%)$ y mediana calidad $(66,9 \%)$, siendo un minoritario $13,4 \%$ que la califica de baja calidad. En concordancia con aquello, los profesores evalúan de manera positiva la calidad de la enseñanza que se entrega en sus liceos, donde el $68,3 \%$ la evalúa como buena o muy buena, de regular un $28,7 \%$ y solo un $2,9 \%$ la evalúa como mala o muy mala.

Teniendo en consideración la alta valoración y evaluación que poseen los docentes sobre el sistema municipal de educación, desde su opinión, las mejoras en la calidad de la educación municipal, 
De los herederos a los desheredados Juventud, capital escolar y trayectorias de vida - O. Dávila, F. Ghiardo

como aspecto más importante, deben contemplar, en primer lugar, las condiciones laborales de los profesores $(57,5 \%)$, expresadas en incentivos salariales y carga horaria. En menor medida $(18,3 \%)$, esta mejora en la calidad de la educación municipal debiera asumir el proceso de enseñanza/aprendizaje.

\subsection{Proyectos de egreso}

Las altas metas en el plano educacional que manifiestan los jóvenes, donde dos tercios expresan sus intenciones de continuar estudios superiores luego de completar su enseñanza secundaria, se tienden a matizar y presentar alternativas complementarias entre las dos dinámicas principales: continuar estudiando o comenzar a trabajar, con las combinatorias entre ambas. Cobran fuerza las opciones vinculadas a un posicionamiento social por la vía del alargamiento de la escolarización, pero también se explicitan nuevamente las posibilidades y oportunidades que pueden tener estos jóvenes en la concreción de sus proyectos de egreso, sea por la vía educacional o laboral, teniendo en cuenta las diferencias internas posibles de identificar entre los estudiantes que asisten al sistema municipal de educación: de género, condiciones socioeconómicas, socioculturales, de rendimiento y desempeño escolar, entre otros.

Como proyecto de egreso de la enseñanza secundaria, los jóvenes señalan que, al culminar la enseñanza media, su proyecto principal se relaciona con la vía de la escolarización, que agregadas las opciones nos arroja una ponderación similar a la consulta sobre su mayor meta educacional $(69,4 \%)$. Las opciones por esa vía van en las formulaciones de continuar estudios superiores $(35,2 \%)$, el trabajar y estudiar al mismo tiempo $(23,7 \%)$, el trabajar un tiempo y luego estudiar (10,5\%). La vía del trabajo obtiene una baja preferencia $(16,1 \%)$, en la opción de encontrar un trabajo estable; como también un 14,5\% plantea que aún no tiene claro su proyecto de egreso. 
El rendimiento escolar de estos estudiantes influye en las opciones que plantean como proyecto de egreso, donde, mientras menor es el rendimiento, más parejos son los porcentajes con que se distribuyen los casos entre los distintos proyectos y mayor el nivel de incertidumbre. La tendencia es que, a medida que aumenta el nivel de rendimiento, menor es el porcentaje de casos que quiere encontrar un trabajo, mayor el de los que quiere continuar estudios superiores y menor el que no lo tiene claro.

Por su parte, la modalidad de enseñanza de los estudiantes también influye en la definición del proyecto de egreso, habiendo una diferencia significativa entre la proporción de la modalidad científica humanista que quiere entrar a trabajar $(7,7 \%)$ y la técnico profesional $(24,8 \%)$. Y, a la inversa, también hay diferencias en los porcentajes de cada grupo que quiere continuar estudios superiores: $48,2 \%$ de los científico-humanistas contra el 24,9\% del técnico profesional. En síntesis: la modalidad produce diferencia en la opción por trabajar, que es mayor entre los técnico profesional, y en la opción por continuar estudios, que es mayor entre los científico humanista.

La escolaridad de la madre y el padre nuevamente muestran su influencia en la definición de los proyectos de egreso de la enseñanza secundaria de los jóvenes, siendo que la alternativa de continuar estudios superiores es la más alta en todos los grupos; sin embargo, es más baja mientras menor es el nivel de escolaridad de la madre. En los grupos que son hijos de madres que no completaron la enseñanza básica, la alternativa de continuar estudios superiores no es significativamente más importante que la alternativa de estudiar y trabajar al mismo tiempo (24,3\%) o encontrar un trabajo (20,5\%). En la medida que aumentan los años de escolaridad de la madre, esta alternativa se va haciendo comparativamente más importante. Nuevamente, el salto se produce al completar la madre la enseñanza secundaria: de 31,4\% para quienes no la completaron, a un $42,6 \%$ que completaron la enseñanza secundaria. Además, el grupo con más alta adhesión a 
De los herederos a los desheredados Juventud, capital escolar y trayectorias de vida - O. Dávila, F. Ghiardo

la alternativa de los estudios superiores, es el de hijos de madres que completaron estudios superiores $(52,8 \%)$.

$\mathrm{Al}$ ver las relaciones que se dan entre las posibilidades de concreción de sus proyectos, con sus proyectos de egreso, tienden a reafirmarse las pocas posibilidades y proyectos de egreso mayoritariamente por la vía educacional.

La definición de un proyecto vital por parte de los jóvenes, en las expresiones que cobran sentido en estos sujetos, puestos en tiempo presente, pero con una idea e imagen de futuro que están comenzando a prefigurar una vez culminada la etapa de enseñanza secundaria, y enfrentados a la decisión y posibilidad de elección de un determinado tipo de proyecto de egreso, consiste en concebir e identificar los posibles caminos a transitar en la perspectiva de las posibles trayectorias de vida a las cuales se ven y se verán enfrentados, donde sin duda las dimensiones del estudio y el trabajo cobran relevancia; pero también otro tipo de experiencias vitales atingentes a la construcción del proyecto vital: la conformación de pareja y familia propia, la emancipación residencial, la independencia económica, la maternidad y paternidad, la inserción laboral, la idea de futuro y sus temores; todo aquello en un contexto y estado de ánimo de gran optimismo por parte de los jóvenes sobre su futuro, con altas metas educacionales explicitadas, pero también con el reconocimiento de ver con preocupación las posibilidades y oportunidades de poder concretar y viabilizar de manera exitosa sus proyectos futuros. Entre estas percepciones positivas e incertidumbres, se desenvuelve el pensar sus proyectos y trayectos de vida.

Una primera aproximación a estas situaciones de vida nos señala que la idea de futuro que más representa a estos jóvenes estudiantes se asocia con la idea de formar una familia con hijos $(44,5 \%)$, y, como segunda preferencia, se muestra indefinición: no lo tengo claro aún (26,9\%). El ámbito de la emancipación residencial, expresada en el vivir solo es tiene una ponderación de 17,8\%; 
y la conformación de pareja, en vivir con pareja, pero no tener hijos $(10,8)$ es la opción menos preferida dentro de estas ideas de futuro. En ambos sexos, la alternativa más frecuente es formar una familia con hijos; sin embargo, hay diferencias significativas en los porcentajes de uno y otro sexo que se ubican en esta categoría: de los hombres, lo hace el 51,3\% y, de las mujeres, un 39\%. Por el contrario, la alternativa de vivir solo es más frecuente entre las mujeres $(21,1 \%)$ que entre los hombres $(13,8 \%)$; y los porcentajes que no lo tienen claro son mayores entre la mujeres $(29,9 \%)$ que entre los hombres $(23,2 \%)$.

La idea de proyecto futuro, visto en relación con la edad en que esperan los jóvenes abandonar el hogar familiar refleja que quienes se proyectan viviendo solos $(22,3 \%)$ o viviendo con pareja sin hijos $(20,5 \%)$ son los que en mayor proporción desean hacerse independientes a edades más tempranas. En la medida que el proyecto vital incluye la formación de familia con hijos, es menor el porcentaje que quiere abandonar el hogar a temprana edad. Por su parte, en el tramo que desea abandonar su hogar con 24 y más años, la mayor proporción de casos está en el grupo que no tiene claro su proyecto $(45,6 \%)$ : no tienen claro qué quieren hacer, pero tienen claro que no quieren irse del hogar familiar. Les siguen quienes quieren formar familia con hijos (44\%); para formar familia parece necesario dar otros pasos previos.

Las opciones de proyectos de futuro y las edades para ser padre o madre se puede decir que, en general, independiente del proyecto que se tenga, la tendencia es aplazar la tenencia de hijos; como también la tendencia general es aplazar el matrimonio. El grupo que más lo quiere aplazar es el que quiere vivir solo $(94,3 \%)$, seguido del que no tiene claro su proyecto $(91,4 \%)$ y quienes quieren vivir con su pareja $(89,2 \%)$. Solo en una proporción relativamente más baja, se ubican en esta alternativa quienes quieren formar familia con hijos (83,1\%).

A la par de la idea de futuro que imaginan, los mayores te- 
De los herederos a los desheredados Juventud, capital escolar y trayectorias de vida - O. Dávila, F. Ghiardo

mores de los jóvenes con relación al futuro se vinculan con la imposibilidad de concretar sus metas y proyectos educacionales, en cuanto a no terminar la enseñanza media $(18,2 \%)$, que corresponde a los estudiantes de menor edad y que cursan los primeros años de la secundaria; y el no poder seguir estudios superiores $(40,2 \%)$. Los otros temores son la dificultad para obtener un empleo, insuficientes ingresos económicos y la imposibilidad de conformar una familia.

El terreno explorado sobre las metas educacionales, los proyectos de egreso de la enseñanza secundaria y la definición de proyectos y trayectos de vida de estos jóvenes, nos plantea que, en ciertos intersticios (dimensión estructural y subjetiva), se van configurando nuevas lógicas de comprensión del ser joven, desde ellos y hacia ellos, que nos llevan a hablar de trayectorias alargadas y nuevas condiciones juveniles en el contexto de la sociedad chilena actual: la juventud no está dada, se construye socialmente (Bourdieu, 2000). La construcción de su condición juvenil atraviesa por un sentimiento de alto optimismo (quizás como rasgo generacional), pero con incertidumbre y temores; la preeminencia de un cambio en los valores sociales de los jóvenes (hacia un legítimo éxito individual, por sobre proyectos de movilidad colectiva); altas expectativas y metas, pero con el reconocimiento de posibilidades inciertas; con el convencimiento del desigual acceso a las oportunidades sociales, marcado por una diferenciación social a la base de una movilidad social reproductora de desigualdades de origen; tensionados entre dos principios: seguridad y autonomía, deseando su apropiación y ejercicio de ambos y, al mismo tiempo, operando en ocasiones con lógicas de racionalidad instrumental para concretar y vivir bajo tales principios.

\section{Bibliografía consultada}


Alba, V. (1975). Historia de la juventud. Barcelona: Plaza y Janés.

Atria, Raúl (2004). «Estructura ocupacional, estructura social y clases sociales». Serie Politicas Sociales No 96. Santiago: CEPAL.

Bourdieu, Pierre (1988). La distinción. Criterio y bases sociales del gusto. Madrid: Taurus.

(1997). Razones prácticas. Sobre la teoría de la acción. Barcelona: Anagrama.

(1998). Capital cultural, escuela y espacio social. México: Siglo XXI.

(2000). Cuestiones de sociología. Madrid: Istmo.

y Jean-Claude Passeron (2003). Los herederos. Los estudiantes y la cultura. Buenos Aires: Siglo XXI.

y__ (1996). La reproducción. Elementos para una teoría del sistema de enseñanza. México: Fontamara.

Camarano, Ana Amélia et al. (2004). «Caminhos para a vida adulta: as múltiplas trajetórias dos jovens brasileiros». Texto para Discussão N¹038. Rio de Janeiro: IPEA.

Casal, Joaquim (1999). «Juventud, transición y políticas sociales». En: La nueva condición juvenil y las políticas de juventud. Barcelona: Diputación de Barcelona.

(2002): «TVA y políticas públicas sobre juventud». Revista de Estudios de Juventud $\mathrm{N}^{\circ} 59$. Madrid: INJUVE.

(2004): «Diez proposiciones sobre juventud». En Rossana Reguillo et al. Tiempo de híbridos. Entresiglos jóvenes México-Cataluña. México: Imj.

, Josep Masjoan y Jordi Planas (1988). «Elementos para un análisis sociológico de la transición a la vida adulta». Política y Sociedad $\mathrm{N}^{\circ}$ 1. Madrid: UCM.

Casassus, Juan (2003). La escuela y la (des)igualdad. Santiago: LOM. CIDE (2003): «IV encuesta a actores del sistema educativo». Santiago: CIDE.

CNME (1995). Informe de la Comisión Nacional para la Modernización de la Educación. Santiago: Universitaria.

Dávila, Oscar; Felipe Ghiardo y Carlos Medrano (2006). Los desheredados. Trayectorias de vida y nuevas condiciones juveniles. Valparaíso: Ediciones Cidpa (segunda edición aumentada).

De Azevedo, Fernando (1949). Sociología de la educación. México: FCE. 
De los herederos a los desheredados Juventud, capital escolar y trayectorias de vida - O. Dávila, F. Ghiardo

Hobsbawm, Eric (1994). La era de la revolución: 1789-1848. Buenos Aires: Crítica.

INJUV Chile (1999). Los jóvenes de los noventa. El rostro de los nuevos ciudadanos. Segunda encuesta nacional de juventud. Santiago: INJUV.

(2002). La eventualidad de la inclusión. Jóvenes chilenos a comienzos del nuevo siglo. Tercera encuesta nacional de juventud. Santiago: INJUV.

(2004). Cuarta encuesta nacional de juventud 2003. La integración social de los jóvenes en Chile 1994-2003. Santiago: INJUV.

Labarca, Amanda (1939). Historia de la enseñanza en Chile. Santiago: Publicaciones de la Universidad de Chile.

León, Arturo y Martínez, Javier (2001). "La estratificación social chilena hacia fines del siglo $x x »$. Serie de Políticas Sociales N ${ }^{\circ}$ 52. Santiago: CEPAL.

Macedo, Beatriz y Raquel Katzkowicz (2001). Educación secundaria: balance y prospectiva. Santiago: UNESCO.

Machado Pais, José (2000). "Las transiciones y culturas de la juventud: formas y escenificaciones». Revista Internacional de Ciencias Sociales No 164. París: UNESCO.

(2002a). «Laberintos de vida: paro juvenil y rutas de salida (jóvenes portugueses)». Revista de Estudios de Juventud $\mathrm{N}^{0}$ 56. Madrid: INJUVE.

(2002b). «Praxes, graffitis, hip-hop. Movimientos y estilos juveniles en Portugal». En Carles Feixa et al. (editores). Movimientos juveniles en la Península Ibérica: graffitis, grifotas, okupas. Barcelona: Ariel.

Martín Criado, Enrique (1998). Producir la juventud. Crítica de la sociología de la juventud. Madrid: Istmo.

MIDEPLAN (2001). "Situación de la educación en Chile, año 2000. Análisis de la VIII Encuesta de Caracterización Socioeconómica Nacional (casen 2000)». Documento No 4. Santiago: MIDEPLAN.

(2004). «Encuesta de caracterización socioeconómica nacional. Casen 2003». Santiago: MIDEPLAN.

MINEDUC (2002). Estadística de educación. Santiago: MINEDUC.

(2003). «Factores que explican los resultados de Chile en Pisa+». Santiago: MINEDUC.

Núñez, Iván y Roberto Martínez (2004). «Classism, Discrimination and Me- 
ritocracy in the Labor Market: the Case of Chile». Documento de Trabajo $\mathrm{N}^{\circ}$ 208. Santiago: Departamento de Economía, Universidad de Chile.

Organización para la Cooperación y el Desarrollo Económico (OCDE) (2004). Revisión de políticas nacionales de educación. Chile. París: OCDE.

Oyarzún, Astrid y Héctor Irrazabal (2006). ¿Quiénes son los jóvenes estudiantes en el Chile actual? Valparaíso: Ediciones Cidpa (en preparación).

PNUD Chile (1998). Desarrollo humano en Chile 1998. Las paradojas de la modernización. Santiago: PNUD.

(2000). Desarrollo humano en Chile 2000. Más sociedad para gobernar el futuro. Santiago: PNUD.

Redondo, Jesús (2005). «El experimento chileno en educación: ¿conduce a mayor equidad y calidad en la educación? Última Década $\mathrm{N}^{\circ} 22$. Valparaíso: Ediciones Cidpa.

Sandoval, Mario (2002). Jóvenes del siglo XXI. Sujetos y actores en una sociedad en cambio. Santiago: UCSH.

Salazar, Gabriel y Julio Pinto (2002). Historia contemporánea de Chile V. Niñez y juventud. Santiago: LOM.

Tedesco, Juan Carlos (2000). Educar en la sociedad del conocimiento. Buenos Aires: FCE.

Universidad de Chile (2004). Compendio estadístico. Proceso de admisión año académico 2004. Santiago: DEMRE.

Wormald, Guillermo y Florencia Torche (2004). «Estratificación y movilidad social en Chile: entre la adscripción y el logro». Serie Politicas Sociales $\mathrm{N}^{\circ}$ 98. Santiago: CEPAL. 